\title{
O processo de retorno entre o Paraná e a Amazônia Legal (1980- 2014): problemáticas territoriais e memória
}

\author{
The return process between Paraná and the legal Amazon \\ (1980-2014): territorial issues and memory
}

Jorge Pagliarini Junior ${ }^{*}$

\begin{abstract}
Resumo
Apresenta-se uma pesquisa sobre migração envolvida nos meandros da relação entre a estatística e sua possível interpretação histórico-antropológica, na qual se constatou a existência de fluxos de deslocamentos reinterpretados por entrevistas orais. Parte-se de um estudo da trajetória de sujeitos que vivenciaram o fenômeno migratório Sul-Norte-Sul do Brasil, especificamente entre Paraná - Amazônia Legal - Paraná no período demarcado de 1970 a 2014, com ênfase nas dinâmicas que envolveram o processo de retorno, ou seja, o fluxo ocorrido a partir de meados da década de 1990, desenrolando-se até o tempo delimitado na pesquisa. Interpreta-se um processo de territorialidade na sua tensão existente entre, por um lado, a importância, e, por outro, as dificuldades do mapear de fluxos, permeados por discursos e políticas que envolvem os deslocamentos, diante de fronteiras materiais e simbólicas vivenciadas por esses sujeitos e apresentadas pelas memórias.
\end{abstract}

Palavras-chave: Migração de retorno; Memória; História Oral.

\begin{abstract}
:
This research is about the migration involved in the relationship between the statistics and its possible historical and anthropological interpretation, in which it was found the existence of reinterpreted displacement flows through oral interviews. Besides, it presents a study of the history of individuals who experienced the phenomenon of migration South-North-South of Brazil, specifically between Paraná - legal Brazilian Amazon- Parana, from 19702014, with emphasis on the dynamics surrounding the process of return, that is, the flow that occurred from the mid-1990s to the defined time on this research. The territoriality process is interpreted through the tension between the importance and the difficulties of mapping flows, which are permeated
\end{abstract}

\footnotetext{
* Doutor em História pela UFGD. Professor do Programa Mestrado Acadêmico em História Pública, do Programa de Mestrado Profissional em Ensino de História e do Colegiado de História da UNESPAR, Campo Mourão.E-mail: palhajr@yahoo.com.br
} 
by discourses and policies involving involve the displacements. In front of material and symbolic boundaries experienced by these subjects and presented by the memories.

Keywords: Migration of return; Memory; Oral History.

\section{Apresentação}

"Quem sabe?"1

A frase "Quem sabe?!” é significativa e já direciona nossa análise, histórica antropológica de fluxos de deslocamentos e os seus apontamentos estatísticos. Foi com ela que Márcia apresentou uma síntese daquilo que argumentaria na sequência de sua entrevista, quando foi perguntada da possiblidade de uma nova migração, resumindo tanto os motivos do retorno quanto a possiblidade de um dia sair novamente do Paraná. ${ }^{2}$ Exemplos como o seu demonstram a espacialidade apresentada em um deslocamento, tipo de processo analisado pela nossa pesquisa a partir do estudo da territorialidade narrada nas e pelas memórias, cujo desafio da sua problematização reside no trabalho de procurar situar as memórias de deslocamentos diante de um modelo de tipos migratórios.

A abordagem da pesquisa, quanto ao seu marco geográfico e temporal, tem estabelecidos os itinerários Sul - Norte - Sul do Brasil, especificamente os itinerários entre Paraná - Amazônia Legal - Paraná durante um processo demarcado no período de 1970 a 2014, aqui estudado pelo recorte do retorno da Amazônia para o Paraná, a partir de meados da década de 1990. A temática da migração de retorno tem a sua base metodológica pautada no cruzamento entre narrativas orais e dados estatísticos. Mais especificamente, nosso posicionamento teórico epistemológico conduz ao reconhecimento de fluxos migratórios, em específico ao fluxo de retorno, considerando para tanto índices migratórios, sua conceituação e aplicabilidade e as experiências de sujeitos neles envolvidos. Por sua vez, a abordagem histórica da trajetória do migrante estrutura-se na interpretação dos múltiplos ritmos e usos do espaço.

\footnotetext{
${ }^{1}$ MÁRCIA. Entrevista cedida ao entrevistador Jorge Pagliarini Junior. Corbélia/PR, 4 jan. 2014.

${ }^{2} \mathrm{O}$ texto parte da releitura dos resultados de uma pesquisa maior, de doutoramento pela Universidade Federal da Grande Dourados (UFGD), na qual apresentamos o fluxo de retorno de paranaenses da Amazônia Legal. $\mathrm{O}$ interesse pela temática da pesquisa deveu-se ao fato de termos vivenciado esse processo de migração.
} 
A apresentação desse objeto de pesquisa segue com o seguinte questionamento: Os fluxos mapeados pela Demografia são compreendidos, apropriados pelas memórias dos entrevistados? Ainda: Quais seriam as possíveis formas de categorização do retorno tendo por base as entrevistas com os próprios migrantes? Por fim: Quais abordagens seriam acionadas para tal empreitada conceitual e metodológica?

Para responder a esses questionamentos dividimos a sequência do texto em dois momentos. No primeiro deles apresentamos nosso posicionamento conceitual diante do cotejamento das entrevistas com estatísticas dos fenômenos migratórios estudados; para tanto, apresentamos o fluxo de retorno - tendo por base os estudos estatísticos do Instituto Brasileiro de Geografia e Estatística (IBGE); destacamos nossa relação de pesquisa com a História Oral - com referências às "memórias divididas", de Portelli, quando estudou as memórias dos moradores da cidade de Civitella Val de Chiana; ${ }^{3}$ problematizamos a noção de narrativa - com relação aos estudos de Ricoeur ${ }^{4}$ e seu entendimento a respeito da narrativa histórica; e ainda, pontuamos epistemologicamente nossos usos dos conceitos de território - a partir dos estudos de Haesbaert, ${ }^{5}$ a propósito do "mito da desterritorialização" e de retorno - com a problematização da noção de retorno de Sayad, ${ }^{6}$ na sua discussão sobre a "angústia do migrante", diante das relações de alteridade.

No segundo momento partimos da subjetividade e da constante ressignificação de memórias - resultantes das entrevistas, e apresentamos uma categorização das formas de retorno. Nesse exercício, defendemos que, se, por um lado, é relevante a divisão do processo de retorno em três categorias por nós percebidas, sendo eles o retorno "planejado", o retorno forçado e o retorno não planejado, por outro lado, essas três "modalidades" não esgotam a pluralidade das memórias dos itinerários narrados pelos entrevistados.

Ambos os momentos da escrita gravitam entre três problemáticas. A primeira problemática é referente ao esforço de busca por representatividade, uma vez que tratamos de um processo marcado por fluxos constatados em décadas de pesquisa, pautados para tanto nas memórias de um grupo que

\footnotetext{
${ }^{3}$ Ver: PORTELLI, Alessandro. 0 massacre de Civitella Val di Chiana (Toscana: 29 de junho de 1944): mito, política, luto e senso comum. In: AMADO, Janaína; FERREIRA, Marieta de Moraes. Usos e abusos da história oral. Rio de Janeiro: FGV, 1996. p. 103-130.

${ }^{4}$ Ver: RICOEUR, Paul. A memória, a história, o esquecimento. Campinas: Edunicamp, 2007. (p.143-301).

${ }^{5}$ Ver: HAESBAERT, Rogério. 0 mito da desterritorialização: do "fim dos territórios" à multiterritorialidade. 6. ed. Rio de Janeiro: Bertrand Brasil, 2011.

${ }^{6}$ Ver: SAYAD, Abdelmalek. O retorno. Elemento constitutivo da condição do imigrante. Travessia, número especial, p. 7-32. São Paulo, janeiro 2000.
} 
totalizou 17 famílias, nosso universo de entrevistas, das quais selecionamos algumas representativas para o momento.

A segunda problemática considera o significado do trabalho com narrativas e, consequentemente, com subjetividades, visto que lidamos com um estudo de memórias e com o cotejamento de diferentes fontes. Aqui consta o desafio de estabelecermos nortes para o debate, e corremos, com isso, o risco de se separar coisas que foram produzidas numa narrativa - leia-se, entrevista - que não as separou (retorno e saída; trabalho e colonização, e a própria estrutura narrativa que muitas vezes não se dá de forma linear).

A terceira problemática parte da compreensão de escalas temporais de migração, sendo a primeira a saída do Paraná e a segunda, a do retorno, rememorada pelas entrevistas e explorada na sequência do texto. Além destas fases vivenciadas pelos entrevistados, somam-se a elas fases migratórias não vivenciadas, como aquela que representa a migração de pais e avós vindos do Rio Grande do Sul e Santa Catarina para o Paraná no período anterior aos anos da década de 1970. Por fim, a própria expectativa da volta para o Norte do país, perspectiva manifestada por alguns dos entrevistados, pode ser considerada como outra escala temporal.

A apresentação das formas de categorização do retorno está estruturada na problematização de fragmentos de três entrevistas, as quais representam, respectivamente, cada um dos modelos de retorno mapeados. ${ }^{7}$ A primeira entrevista, com duração de aproximadamente setenta minutos, apresenta a trajetória da Marcia; ela migrou para Tucumã- Pará, no ano de 1993, após ter recebido o convite de seu irmão e de seu pai, emigrados para lá um ano antes dela, e acabou retornando poucos meses depois do retorno deles ao Paraná, em 1999. Na sua entrevista, agendada apenas uma vez e gravada dias depois na sua casa, ela destaca o fato de ter trabalhado pela primeira vez em um cargo almejado: o de secretaria na prefeitura Municipal daquele município, onde era conhecida como "Dona Marica". Após migar do estado do Pará Marcia morou seis anos no estado de Santa Catarina e então retornou para a cidade de Corbélia - Paraná.

A segunda entrevista apresenta a narrativa da Hélide, cujo contato para a entrevista se deu na casa de sua mãe, com quem reside atualmente.

\footnotetext{
${ }^{7}$ Avaliar o papel do paranaense (sulista) pela sua dinâmica territorial, isso implicou o destaque apresentado pelos entrevistados, por exemplo, nas suas contribuições ao desenvolvimento a partir do extrativismo da madeira e do envolvimento com a agricultura entre as décadas de 1980 aos dias atuais. Foram entrevistados migrantes de diferentes ramos e portes empresariais, como madeireiro, proprietários de oficinas mecânicas, além daqueles que foram para trabalhar como empregados, inclusive para outros migrantes paranaenses, profissionais liberais, professores, engenheiros, arquitetos e trabalhadores que partiram sem profissão definida.
} 
Na semana seguinte realizamos a entrevista que durou aproximadamente 90 minutos. Aos sessenta e sete anos ela afirma ter vivido anos felizes no Pará e Tocantins, entre 2000 e 2005. A relação dela com o Norte ocorreu, segundo ela, ainda nos anos de 1980, quando seus irmãos adquiriram terras no estado Pará. Hélide organiza a sua fala a partir das dificuldades familiares, como aquela decorrente da sua separação conjugal, quando ainda vivia em Corbélia, até a morte de seu irmão, que vivia no Pará, e a morte do seu neto, motivo pelo qual precisou retornar para o Paraná.

A terceira entrevista apresenta a trajetória do Márcio. O contato foi realizado meses antes e a entrevista ocorreu no seu local de trabalho. Em pouco mais de uma hora ele organiza a sua fala partindo de outras experiências migratórias que vivera desde a idade de quatorze anos, quando deixou a casa dos pais para treinar em um clube de futebol do município de Londrina, Paraná. Dois anos depois desse momento iniciou a sua carreira profissional a qual se estendeu por um intervalo de oito anos, tendo durante este período atuado em clubes de São Paulo, do Japão e da Alemanha. Essas experiências teriam facilitado, segundo ele, a escolha da opção pela migração para o Norte, para o Estado de Rondônia; passados cinco anos ele retornou para Ubiratã, Paraná.

\section{O retorno nas memórias e nas estatísticas}

Constava no apêndice do material citado anteriormente e base para nossa compreensão estatística do processo de retorno, publicada pelo IBGE, ${ }^{8}$ um questionário tratado como uma proposta do IBGE para futuras investigações aos domicílios, o qual agregava ao estudo de redes migratórias o quesito motivação "[...] Esta parte do questionário procura identificar qual a percepção do migrante em relação ao motivo que o levou a empreender o movimento migratório". ${ }^{9}$ Embora o documento admitisse que: "Mesmo sabendo-se da limitação que se tem em buscar apreender os aspectos motivacionais da migração em um levantamento não qualitativo", ${ }^{10}$ o seu esforço foi significativo. No documento lê-se:

Além das motivações exploradas na PNAD 2001, foram incluídos aspectos associados à violência, no lugar de origem, e a expectativa continuada de acessar bens e/ou serviços, no lugar de destino. Espera-se que esses fatores

\footnotetext{
${ }^{8}$ Ver: OLIVEIRA, Luiz A. Pinto de; OLIVEIRA, Antônio T. Ribeiro de (Orgs.). Reflexões sobre os deslocamentos populacionais no Brasil. Rio de Janeiro: IBGE, 2011.

${ }^{9}$ Ibidem. p. 99.

${ }^{10}$ Ibidem.
} 
possam proporcionar a uma melhor apreensão sobre as motivações que levam o indivíduo a migrar.

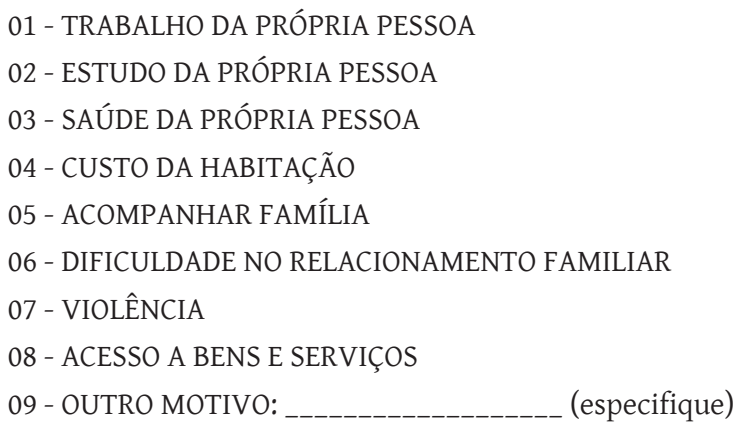

Este quesito foi implementado de forma experimental no teste piloto da PNAD Contínua. Caso os resultados do teste não sejam satisfatórios, a pergunta deverá ser excluída da versão definitiva do Suplemento Migração. ${ }^{11}$

Essa limitação no acionar da subjetividade via formulário de pesquisa pode ser potencialmente superada no trabalho com a História Oral. E foi diante da possiblidade da interpretação subjetiva do fluxo migratório, que procuramos categorizar os tipos de retorno a partir de nossa amostra, pontualmente, 17 entrevistas, 25 entrevistados e aproximadamente 100 familiares, mencionados diretamente pelos entrevistados.

O conjunto de 17 entrevistas totaliza, aproximadamente, 25 horas de gravação. A metodologia da produção dessas entrevistas seguiu um tipo de organização pautada numa rede de contatos. Ela foi constituída de três camadas de indicações, com as quais chegamos espacialmente ao recorte de seis municípios da região oeste e um da região Centro Ocidental do Paraná. ${ }^{12}$ A primeira camada de entrevistas se deve aos nossos contatos de familiares e de sujeitos conhecidos, e ocorreram na cidade de Corbélia, Paraná, pequena cidade de aproximadamente oito mil habitantes, de onde saíram entre as décadas de 1970 e 1990 parte de seus moradores e para onde retornaram em meados da década de 1990 entre eles, nossos familiares. Sucessivamente, os entrevistados da segunda camada, e dela fazem parte as três entrevistas ora analisadas, foram indicados pelos entrevistados da primeira, e os da terceira camada, pelos os da segunda. Nessa organização, incialmente tivemos o intuito de produzir histórias de vida, no entanto, as narrativas da pesquisa

\footnotetext{
${ }^{11}$ Ibidem. p. 101.

${ }^{12}$ As entrevistas que estruturam nossa pesquisa podem ser resumidas numa perspectiva segunda a qual a História Oral trata-se de uma metodologia. Ver: FERREIRA, Marieta M.; AMADO, Janaina; (Org.) Usos e abusos da história oral. Rio de Janeiro: 8. ed. FGV, 2006.
} 
e as dinâmicas das entrevistas encaminharam a nossa abordagem para uma história temática. ${ }^{13}$

Essa afirmativa responde, em parte, nossa pergunta central, qual seja, se os entrevistados compreenderam e, respectivamente, se apropriaram do entendimento da existência de fluxos migratórios para então narrarem suas trajetórias, pois eram por nós procurados para tratarem de um movimento migratório do qual faziam parte; portanto, como foram antecipadamente informados de tal foco da pesquisa já se diziam migrantes retornados. Todavia, a afirmação não delimita e resolve nossa problemática de pesquisa, e conforme perceberemos na sequência do texto, a maneira como os entrevistados se aproximaram das trajetórias de outros migrantes se deu de forma polissêmica. Antes da apresentação dos fragmentos das entrevistas, necessitamos abordar aspectos do fluxo de retorno, escopo desse primeiro momento do texto.

\section{O fluxo e o seu estudo.}

A nossa compreensão - estatística - do fluxo de retorno foi fundamentada na obra mencionada acima, "Estudo e Análises, Informações Demográfica e Socioeconômica Número 1: reflexos sobre os deslocamentos populacionais no Brasil", publicada pelo IBGE..$^{14}$ A publicação se diz pautada na transversalidade dos estudos de diferentes áreas das Ciências Sociais Aplicadas, ${ }^{15}$ está ancorada numa revisão dos índices e dos indicativos de recenseamentos ocorridos a partir de 1970 até os indicativos do recenseamento de 2010 e apresenta as novas configurações dos deslocamentos populacionais - 2001 a 2010. Entre as principais configurações dos fluxos migratórios apresentados pelo IBGE está constatada, desde os últimos anos 1980, uma significativa modificação estrutural tendo destaque as migrações de retorno:

Embora em níveis distintos nas pesquisas, os estados das regiões Nordeste e Sul apresentaram as maiores participações relativas da migração de retorno no total da imigração para seus estados nos três momentos analisados (2000, 2004 e

\footnotetext{
${ }^{13}$ MEIHY, José Carlos Sebe Bom; HOLANDA, Fabíola. História oral: como fazer, como pensar. São Paulo: Contexto, 2007.

${ }^{14} \mathrm{~A}$ preocupação com a contextualização desses processos está dividida em dois momentos: o primeiro empenha-se com o objeto da pesquisa, as narrativas orais do movimento de retorno ao Paraná, correspondentes ao processo já demarcado pelo Instituto Brasileiro de Geografia e Estatística (IBGE) a partir dos anos de 1990; o segundo com o estudo do processo de migração entre o Paraná e a Amazônia entre 1970-1980, recorte que recorre ao diálogo com outro anterior, tempo esse das construções políticas dos anos de 1950 e que também interferiram em ambas as regiões.

${ }^{15}$ No caso do estudo, envolveu ainda pesquisadores da Coordenação de Geografia, da Diretoria de Geociências e da Unidade Estadual de Minas Gerais que foram reunidos no Grupo Transversal de Estudos do Território e Mobilidade Espacial da População - Gemob.
} 
2009), destacando-se, no quinquênio 1999/2004, Maranhão, Piauí, Pernambuco e Bahia, além do Paraná e Rio Grande do Sul como estados que superaram os $20 \%$ de retornados no total de imigrantes. [...] Em 2009, os estados em que a migração de retorno foi mais expressiva, superando os $20 \%$ do total de imigrantes, foram Rio Grande do Norte, Paraíba, Pernambuco, Sergipe, Minas Gerais, além do Paraná e Rio Grande do Sul. ${ }^{16}$

\section{As causas de tal contexto foram sintetizadas da seguinte maneira:}

I- a inversão das correntes migratórias entre os Estados de Minas Gerais e do Rio de Janeiro; II- a redução da atratividade migratória exercida pelo Estado de São Paulo; III- o aumento da retenção de população na Região Nordeste; IV- os novos eixos de deslocamento às cidades médias no interior do País; V- o aumento da importância dos movimentos pendulares; VI- o esgotamento da expansão da fronteira agrícola; VII- a migração de retorno do Paraná. ${ }^{17}$

A partir dos indicativos do Censo Demográfico de 2010, o trabalho supracitado problematizou eixos de crescimento, tendo por base os totais populacionais para os municípios investigados em 2010, cotejados com os totais observados em 2000, resultando assim na apresentação do cálculo da taxa média geométrica anual de crescimento. ${ }^{18}$ Aqui nos interessa o índice relacionado ao "saldo líquido", resultante da diferença entre o índice de entrada e (imigrantes) e de saída (emigrantes) de pessoas do estado representado.

Essa análise nos conduz aos índices dos estados numa abordagem regional. No caso dos estados que integram a região da Amazônia Legal pôde ser constatado saldo líquido migratório (índice da diferença entre emigrantes e imigrantes no respectivo período) estável entre os anos de 2004 a 2009, mantendo-se suas unidades federativas, algumas com baixo índice positivo, como no caso de Rondônia, e outras com baixo índice negativo, como no caso de Acre e do Pará. Em relação à região Sul essa realidade não foi constatada durante o período analisado. No caso do Paraná, o estado passou neste intervalo de um saldo líquido negativo $(-0,02)$ para um positivo $(0,08)$, constando-se, principalmente se considerarmos o seu índice negativo referente ao ano de $2000(-0,06)$, a intensificação da imigração para o estado.

\footnotetext{
${ }^{16}$ OLIVEIRA, op. cit., p. 39.

${ }^{17}$ Idem. p. 12.

${ }^{18}$ Debate está estruturado em três capítulos. A primeira parte trata das informações provenientes do Censo Demográfico 2000, mapeando os fluxos observados no país no quinquênio 1995/2000, enfatizando as trocas populacionais, e construindo o Índice de Eficácia Migratória e de imigrantes de retorno. A segunda parte analisa os dois períodos abarcados pelas PNADs, 2004 e 2009, com ênfase nas tendências observadas ao longo dessa década, como as "trocas inter-regionais" e o Índice de Eficácia Migratória e dos imigrantes de retorno. E a terceira parte analisa as taxas de crescimento populacionais dos municípios referentes ao período de 2000-2010.
} 
Relacionado ao índice de eficácia migratória, temos o índice referente à migração de retorno. Evidentemente parte dos emigrantes que abandonam um estado pode ter migrado para o mesmo estado de onde saíram anteriormente, ou seja, estariam retornando. Os estados do Maranhão, do Rio Grande do Sul e do Paraná constataram, respectivamente, índices de 43\%, 39,23\% e 37,86\% do total de seus migrantes sendo retornados, e se destacaram no cenário nacional.

Esse conjunto estatístico nos serviu como contexto para a sequência da pesquisa ancorada nas memórias de sujeitos que vivenciaram parte desses deslocamentos. Aqui residiu outro desafio da nossa análise, o da necessidade de um posicionamento diante da problemática da representatividade das entrevistas. E a própria metodologia da História Oral nos serviu de base para tal problematização.

Para Mercedes Villanova, ${ }^{19}$ é produtivo o estudo de fontes orais pautado no diálogo com a estatística. Nos seus estudos sobre o analfabetismo, a autora destaca que a História Oral propõe a existência de uma relação entre a "estatística fina" - ou estatística da estatística - com a fonte oral que resultaria na produção de "uma história útil", pautada no diálogo que rege a entrevista enquanto um ato político, o qual tende tanto para a diferença quanto para a unidade entre entrevistador e entrevistado. ${ }^{20} \mathrm{~A}$ estatística possibilitaria, assim, o entendimento do contexto social e serviria para a produção das perguntas que estruturam uma entrevista. ${ }^{21}$

Noutra significativa abordagem, ressaltamos que a construção das entrevistas considerou o caráter dialogal, a espiral esperada por Portelli quando apontou da entrevista a interferência do entrevistador, a desconfiança do entrevistado e as expectativas do entrevistado e do entrevistador com os possíveis leitores de uma entrevista. ${ }^{22}$ Em outra obra, Portelli interroga e explana a proposta de "memórias divididas" ao apresentar as memórias dos moradores da cidade de Civitella Val de Chiana a respeito do massacre de junho de 1944, quando civis italianos foram mortos em um único dia pelos soldados alemães, em retaliação à morte de soldados alemães pela Resistência italiana. ${ }^{23}$ Portelli

\footnotetext{
${ }^{19}$ VILANOVA, Mercedes. Pensar a subjetividade: estatísticas e fontes orais. In: FERREIRA, Marieta de Moraes (Org.). História oral e multidisciplinaridade. Rio de Janeiro: Diadorim, 1994.

${ }^{20}$ Ibidem p. 47.

${ }^{21}$ A autora destaca sua aproximação com a linguística para, de certa forma, produzir (isso com o auxílio de uma equipe interdisciplinar) a quantificação das entrevistas, com aproximações entre os resultados alcançados - fontes insubstituíveis - obtidas a partir da maneira como se passa e se recebe uma informação. ${ }^{22}$ POTELLI, Alessandro. Tentando aprender um pouquinho: algumas reflexões sobre a ética na História Oral. Projeto História, São Paulo, (15), abr. 1997. pg. 29.
}

${ }^{23}$ PORTELLI, Alessandro. O massacre de Civitella Val di Chiana (...), op.cit. 
problematizou essa que era a principal construção teórica e metodológica sobre o estudo do massacre. Assim, de um lado, haveria uma memória "oficial" que comemorava o massacre como um episódio da Resistência italiana, ou seja, como exemplo do nacionalismo italiano e, por outro, uma memória local, comunitária, preservada pelos sobreviventes - do luto e crítica à resistência que se deu naquela época da guerra. Portanto, uma memória a priori ideológica - nacionalista, contra uma memória subjetiva e do luto - local. Os limites dessa leitura, segundo o autor, estão na sua conotação binária e foram problematizados frente aos resultados de sua pesquisa, na qual aponta para a multiplicidade de memórias e de construções entendidas a partir de um estudo processual - todas elas ideológicas e subjetivas.

Nesse movimento, as narrativas orais decorrentes das entrevistas direcionaram o nosso estudo à observação da relação entre a construção do conhecimento histórico e a narrativa que dele resulta. Na obra A Memória, a História e o Esquecimento, ${ }^{24}$ Paul Ricoeur apresenta um caminho para a discussão a respeito da construção do conhecimento histórico ao enfatizar o caráter narrativo desse conhecimento. ${ }^{25} \mathrm{O}$ autor ressalta a contribuição da análise do discurso no intento da utilização das fontes, e enfatiza desse processo a necessidade da releitura das condições sociais dos sujeitos, ou seja, da compreensão dos lugares sociais assumidos durante a pesquisa. Caberia assim ao pesquisador ter de lidar tanto com momentos da consciência quanto com o lugar social por ele ocupado. Nesse processo, o esquecimento e a imaginação não implicariam perdas, vale ressaltar. Ancorados em Ricoeur avaliamos a própria construção das entrevistas, naquilo que ele indica do entendimento "das fases" de documentação, explicação/compreensão e representação fases estas que se visitam.

Assim atentamos aos tipos de narrativas dos itinerários realizadas pelos entrevistados, e elas representaram os resultados de uma relação com o espaço numa acepção que extrapola a sua configuração administrativa, sem que isso fosse desconsiderado no contexto analisado. $\mathrm{O}$ espaço, aqui, entendido pela

\footnotetext{
${ }^{24}$ RICOEUR, op.cit.

${ }^{25} \mathrm{~A}$ obra retoma o significado de debates clássicos, como as contribuições da Psicanálise, as críticas ao próprio sentido de História lançadas por Nietzsche e o debate contemporâneo com Certeau a respeito da Operação Histórica. De acordo com a Hermenêutica Fenomenológica de Ricoeur temos um delineamento dos três momentos da consciência: a memória, a história e o esquecimento. Nisto conceitua a consciência, voltado à crítica do essencialismo e do materialismo mecânico, definindo-a não como um reflexo, mas como algo orientado para as coisas. Essa construção fenomenológica soma-se a sua perspectiva hermenêutica, contrária ao semiotismo fechado. 0 fenômeno retoma a necessidade de interpretação e, assim, temos o ser interpretando aquilo que, a priori, se apresentava estranho (enigma) ao seu mundo. Esse semiotismo nos remete ao limite do tratamento de uma entrevista apenas enquanto um texto/transcrição.
} 
conquista, portanto, um território, foi também construído semanticamente, e a ele foi atribuído uma conotação de lugar. Lugar distante e desconhecido, conquistado em diferentes graus, intensidades, e atividades - pelo ganho cultural; pelo reconhecimento público via trabalho; pelo ganho financeiro obtido com a migração.

Essa análise demandou uma definição teórica de território. Para tanto, recorremos aos estudo de Haesbaert na sua apresentação da amplitude do conceito de "território", ou da relação entre território e o conceito de "identidade". ${ }^{26}$ Aproximando-se de uma perspectiva dita integradora do território, sua análise, diferentemente da visão de território total, considera o espaço e as relações sociais a partir da leitura pautada tanto na semiotização quanto nos aspectos materiais, sem para tanto colocá-los em campos dicotômicos. E, já dissemos, acreditamos que essa reconstrução de territórios responda a uma busca material e simbólica. Como afirmou Haesbaert, território, em qualquer acepção, está associado ao poder material, político, mas também, simbólico, pautado no ato da apropriação. ${ }^{27}$ Também, no nosso caso, o lugar ao qual se deseja ou não retornar.

De certo modo, essa afirmação territorial ancorada na relação construída entre o mérito pessoal e as conjunturas econômicas, ou seja, entre o falar de um processo migratório, notadamente apresentado nas entrevistas pelo esforço da apresentação de políticas e conjunturas econômicas e o falar de si, agregou a nossa análise a refutação de explicações tomadas pelo campo puramente econômico.

O caminho adotado para lidarmos com esta relação entre o desempenho pessoal e as conjunturas enfrentadas partiu do reconhecimento e agendamento de identidades diante do trabalho de análise discursiva - narrativas orais, e correspondeu ao mapeamento de sistemas de classificação a partir dos quais percebemos o significado da diferença presente nos processos de construção de identidades ${ }^{28}$ Especificamente, tais representações sociais referiram-se na

\footnotetext{
${ }^{26}$ HAESBAERT, op. cit.

${ }^{27}$ Nesse diálogo entre múltiplas dimensões do estudo do espaço, o autor discute o processo de construção de territorialidades e adota as problemáticas de territórios numa perspectiva polissêmica para estudar o espaço geográfico e suas disputas, em múltiplas escalas de observação. Ao dialogar com a filosofia de Deleuze e Guattari, demonstra como o conceito de territorialidade contribuiu para a desconstrução do mito da desterritorialização. Assim, suas preocupações vão além da leitura filosófica e indicam um plano político. Nessa perspectiva, o conceito de território apenas faz sentido se experimentado nos determinados contextos - tempo e espaço. $O$ autor se apropria de uma concepção filosófica - rizomática - para analisar os agendamentos de corpos - maquínicos - e de enunciados - semânticos p. 127).

${ }^{28}$ WOODWARD, Kathryn. A identidade e diferença: uma introdução teórica e conceitual. In: SILVA, Tomaz. T. (Org). Identidade e diferença: a perspectiva dos estudos culturais (7 $7^{\mathrm{a}}$ ed.) Petrópolis, RJ: Vozes. 2014. p. 7-72.
} 
nossa pesquisa, sobretudo, ao reconhecimento da condição de migrante e da expectativas pelo retorno. $\mathrm{E}$ falar de si remeteria em todos os casos ao falar àqueles que ficaram.

Para Sayad ${ }^{29}$ o estudo do retorno deve considerar nas suas premissas os riscos de se pensar a migração apenas pelo viés econômico, sem se considerar o impacto do Estado, algo que remeteria a pesquisa à despolitização dos sujeitos, ou ainda, ao risco de se "tecnicizar" o social. Cabe ressaltar, a nostalgia do retorno à terra natal, lugar sacralizado na e pela memória, decorre da impossibilidade da volta no tempo, pois se alcança a volta ao espaço natal, mas não ao tempo, e o espaço já é outro. Logo, a vida do migrante está marcada pela possibilidade, ou melhor, pela angústia do retorno:

O imigrante só deixa de sê-lo quando não é mais assim denominado e, consequentemente, quando ele próprio assim não mais se denomina, não mais se percebe como tal. E a extinção desta denominação apaga, a um só tempo, a questão do retorno inscrito na condição de imigrante [...]. ${ }^{30}$

Uma condição atribuída pelos nossos entrevistados em diferentes alcances, conforme veremos mais adiante.

Essa análise nos foi cara, principalmente pelo fato dela sugerir caminhos para a interpretação do pós-retorno. E, nas entrevistas, nelas transpareceu a percepção de que as narrativas não se limitaram ao narrar do período referente ao tempo vivido fora de casa, mas também das maneiras como foram recebidos, na volta para casa. Retomando a obra de Sayad, chegamos a um paradoxo vivido no pós-retorno, quando a ausência deveria ser recompensada pela conquista espacial e financeira, sem que isso viesse a encobrir a ausência gerada com a saída (emigração). Entre os exemplos por nós levantados, os entrevistados destacaram os significados das conquistas econômicas e/ou culturais, além da própria coragem em se aventurar, em se arriscar. Todas essas experiências nos permitiram categorizar o retorno.

\section{Dos motivos e da categorização do retorno}

Uma vez apresentado o panorama do processo de migração estudado, a nossa abordagem a partir da História Oral, um posicionamento conceitual

\footnotetext{
${ }^{29}$ SAYAD, op. cit.

${ }^{30}$ Idem. p. 11. Importante destacarmos que o referido estudo, além de um panorama introdutório a respeito do contexto de migrações, ou das características genéricas do fenômeno migratório - entre Europa e países da África e América - abordou de maneira mais específica o exemplo da migração (migração e imigração) de argelinos durante e logo após o contexto de guerras pelas independências nos anos de 1950 e 1960.
} 
da leitura espacial dos itinerários e do significado do retorno, passaremos aos modelos de retorno por nós mapeados.

Do conjunto de 17 entrevistas, das quais três serão analisadas na sequência, quatro foram representadas tendo elas o retorno como elemento significativo e planejado durante os preparativos para a migração; quatro foram representadas pelo retorno forçado; e as restantes demonstraram o fato do momento do retorno não ter sido definido quando da saída do estado do Paraná. Cada uma das três entrevistas discutidas na sequência é representativa de um modelo de retorno aqui definido. Com esse intuito, apresentamos um modelo para o estudo do retorno pautado em três categorizações.

Paradoxalmente, procuramos evidenciar a polissemia que constituiu o fenômeno migratório, mesmo diante da nossa tentativa da sua categorização. Dos três direcionamentos que resumem a opção pelo retorno, no primeiro caso, o retorno foi em parte planejado já na partida, e os sujeitos destacaram que esse planejamento fora repensado durante o tempo em que estiveram distantes do Paraná, quando, nesse interim, reconsideraram o tempo necessário para alcançar, entre outros objetivos, a estabilidade econômica. No segundo caso, destacamos o exemplo dos entrevistados que não tinham o desejo do retorno e só o fizeram devido a questões como a de doença na família, ou seja, um retorno forçado. Por último, o caso daqueles que não tinham o objetivo definido de voltar, e que chegaram a cogitar viver em definitivo fora do Paraná, mas, por diferentes situações, acabaram retornando e não descartam a possiblidade de novas migrações. Dentre esses três modelos podemos distribuir todas as entrevistas produzidas pela nossa pesquisa. Diferentemente do que se possa projetar a priori, não apenas na terceira situação, mas sim, nas três, negou-se o pragmatismo da migração.

\section{Do retorno "planejado".}

No caso de Márcia, deixar Tucumã/PA significou cumprir em parte um planejamento e para narrar a sua situação, ela necessitou destacar aquilo que "deixou para trás". Ao ser perguntada a respeito dos momentos de férias, no Paraná, respondeu:

Márcia: E deu aquela vontade de voltar, que se você (...) que nem, se você tava lá, você tava lá dentro, você tá centralizado ali, eu gosto daqui, só que a partir do momento que você vinha passear pro Paraná, dai você já ficava com aquele remorso, sabe, na hora de voltar: "Se eu voltar pra aquele lugar de novo?" Essas estradas (...)

Entrevistador: E você sempre vinha passear nos finais de ano? 
Marcia: É, e daí tô com essa base mais forte pra cá, né. Daí, depois que chegava lá, começava a trabalhar de novo já caía na rotina. ${ }^{31}$

De certa forma, a angústia pelo retorno era amenizada pelo trabalho, sendo reificada nos momentos de férias e visita ao Paraná. O seu planejamento estaria atrelado ao retorno do pai e do irmão, com os quais conviveu pelo período de seis anos no Pará:

Entrevistador: Se o Moisés [irmão] tivesse continuado por lá, você ficaria?

Márcia: Acho que sim. Quem sabe?! Porque daí eu ficava muito sozinha lá. Daí todo mundo foi embora, falei: "Ah, eu não vou ficar sozinha aqui, não. Vou terminar, vou fazer meu acerto!”. E fui. Tanto que daí meu acerto eu dei entrada num lote em Santa Catarina. Daí lá nós começamos, eu e meu marido, trabalhando os dois e... fomos fazendo nossa casa.

Entrevistador: Naquela época você não era casada?

Márcia: Não.

Entrevistador: Você conheceu seu marido aqui?

Márcia: Conheci aqui [no Paraná]. Daí eu fui embora por causa dele. A gente tinha terminado, daí eu fui pra lá. Aí mudou os motivos, né, e ele foi pra Santa Catarina. Nós nos achamos de novo seis anos depois. [...] Daí ficamos por cartas, até eu terminar meu serviço e poder vim, eu também não ia abandonar, assim, eles [prefeitura onde trabalhava] na mão também, daí final de mandado não contrata ninguém, fica chato, né, aí resolvi vir e vim. Daí fui pra Santa Catarina e recomecei de novo. ${ }^{32}$

"Quem sabe?!”. E quem sabe o futuro marido, ex-namorado do Paraná, não a tenha influenciado na decisão; afinal, somente ali "mudou os planos"; e quem sabe o ganho suficiente para comprar o almejado terreno, uma vez surgido com o valor do acerto, também tenha grande influência na decisão pelo retorno.

Ao que nos parece o "lá" foi lembrado primeiramente pelo trabalho, lá onde "quase se matou de trabalhar", mas não apenas, pois também foi lembrado como o lugar onde "era bom", pela natureza, pelas muitas amizades, e onde era conhecida por Dona Marcia: "até um dia um guarda veio pra mim, que daí quando a mulher ganha nenê eles tem direito a cinco dias né [ao tratar de seu cotidiano de trabalho], pra ficar em casa né, aí um guarda veio falar pra mim assim: 'Dona Marcia (...)”'. Talvez não fosse apenas uma questão de lugar, mas de momento, e, nessa lógica, agora, mais velha, com certo capital conquistado, conjecturou que fosse aquele, enfim, o momento de

\footnotetext{
${ }^{31}$ MÁRCIA, op. cit.

${ }^{32}$ Idem.
} 
migrar. De qualquer forma, no seu exemplo o planejamento não correspondeu exatamente àquilo planejado na saída do Paraná, anos antes do retorno. A reconciliação com o namorado, posteriormente seu marido, o ganho para compra do terreno, e o retorno de seu pai e irmão serviram de explicação para a volta para a região Sul; e o reconhecimento no trabalho explica a dificuldade em tomar tal posicionamento, presente nas expectativas da migração, mas desvinculado de certezas e pragmatismo.

\section{Do retorno forçado}

Outro tipo de posicionamento aparece nas entrevistas daqueles que, diferentemente do caso anterior, não pretendiam voltar. E, se aqueles que partiram com um tempo já determinado de ausência destacaram dúvidas e circunstâncias, esses são apresentados pelos acontecimentos que estavam totalmente desconsiderados tempos antes de ocorrerem. Hélide destacou o modo como problemas relacionados à saúde interferiram na decisão pelo retorno, sendo obrigada a voltar no ano de 2005, passados cinco anos de sua saída do Paraná.

O exemplo de retorno forçado é expresso no relato de Hélide quando ela apresentou uma positivação da sua relação com a atividade que desenvolveu no Tocantins, uma lanchonete localizada nas margens do Rio Tocantins, atividade interrompida tragicamente:

Porque em julho lá, junho e julho, é o forte de praia, né. Julho. Aqui é inverno e lá é o forte de praia e a gente ficou lá um tempo, depois aconteceu que a minha filha teve um menino temporão e eu tive que voltar pra ajudar a cuidar desse menino. Porque ele nasceu com problema do coração. E o médico falou: "Ele pode durar três anos e pode falecer de uma hora para a outra". Então a gente tinha que tomar os cuidados, muito cuidado. Acabei vendendo lá e vim lutando pra cá, de novo. Aí ficamos três anos aqui com ele, quando completou três anos resolveram fazer a cirurgia do menino, do coração. Fez a cirurgia na sexta, quando foi amanhecer, domingo, ele faleceu.

[...] Ele gostava de usar chapéu, que nem eu gostava de usar na fazenda. Daí a gente ficou... Ah, nossa! Eu esqueci até de contar que aquela vez que nós estava morando ali em Corbélia mesmo, [antes de migrar] eu já tava, tava meio discutindo com o meu marido porque eu sabia que ele tinha um caso com outra mulher e acabou eu mandando meu filho pro, pra Bahia. Esqueci de falar. [...] Daí eu resolvi ir lá pra Tocantins e ficar lá no Pará, mas depois por causa do menino eu tive que voltar, né. Aí, depois, aconteceu que eu fiquei aqui em Corbélia um tempo, eu morava em Corbélia e meu filho quis que eu viesse morar em Cascavel. Vim morar em Cascavel, aí fui morar em Cascavel e minha nora também estava esperando nenê e perdeu. Aí fiquei um tempo em Cascavel, tive que voltar pra Corbélia por causa desse problema da minha mãe, [...] vai fazer 
um ano em setembro que aconteceu a primeira vez que ela ficou ruim, né, e de lá para cá, sempre, sempre, sempre tratamento, a gente faz das tripas coração e não tem jeito, cada dia pior, agora tá ficando delirando, delirando sabe. [...].

Entrevistador: Você pensa em voltar um dia?

Hélide: Eu penso, e se eu não estou viajando é por causa da mãe; por causa da mãe, dos filhos (...). ${ }^{33}$

Toda a carga de ressentimentos marca a entrevista. O fragmento extenso foi mantido para que pudéssemos demonstrar como o retorno foi tão inesperado quanto a partida do estado e ambos foram motivados por problemas familiares. A saída rumo ao Tocantins deveu-se a sua separação conjugal, e o motivo de seu retorno, devido aos cuidados do neto que viera a falecer. E foram problemas familiares que a impediram (e impedem) de voltar para o Tocantins: a gestação interrompida da sua nora, e a doença de sua mãe, a qual se encontra atualmente sob os seus cuidados.

O exemplo nos possibilita concordar que, conforme discutido anteriormente, em alguns casos o retorno ao Paraná não era mais uma meta, pois o migrante já adaptado não se vê mais na situação de migrante. A possibilidade de outras migrações destacadas por ela exemplifica isso.

\section{Do retorno não planejado.}

Dentre os migrantes que nem planejaram o retorno nem tampouco o descartaram naquele momento da saída do Paraná, temos o caso de Márcio que migrou em 2002 junto com a mulher e filho para Rondônia e lá viveu por cinco anos. Para falar de si enquanto migrante, após ter sido questionado a respeito dos motivos da sua escolha pela migração para o estado de Rondônia, ele procurou apresentar sua trajetória desde criança e alertou para o fato de que, desde jovem, sempre migrou, seja por motivos profissionais ou culturais: "A minha mãe, por exemplo, ela já era uma pessoa que ela sabia que eu já não tava mais com ela, né". ${ }^{34}$ Quando jogador de futebol profissional passou sua juventude fora de casa, oito anos no total, vivendo inclusive uma temporada no Japão e uma na Alemanha. Quanto ao contexto da migração para Rondônia e do seu posterior retorno ao Paraná, Marcio ressalta a dificuldade com a adaptação climática, e o almejado e agora alcançado emprego público.

O retorno veio num momento quando Marcio e sua esposa já estavam se adaptando - ao clima, aos moradores, à própria geografia do lugar, como

\footnotetext{
${ }^{33}$ HÉLIDE. Entrevista cedida ao entrevistador Jorge Pagliarini Junior. Corbélia/PR, 17 jan. 2014.

${ }^{34}$ MÁRCIO. Entrevista cedida ao entrevistador Jorge Pagliarini Junior. Ubiratã/PR, 19 dez. 2014.
} 
ele próprio destacou ao responder a respeito das supostas dificuldades e estranhamentos advindos do processo de migração: "E foi nesse momento que eu estava bem empregado e ela [sua esposa] estava desempregada, que a minha sogra convidou pra voltarmos pro Paraná, dando um emprego pra minha esposa". ${ }^{35} \mathrm{Em}$ forma de balanço de sua história, narrada "com prazer" pelas experiências migratórias, o apego pelo Paraná contrasta com o espírito aventureiro: "Mas se eu tivesse que morar em qualquer um desses estados hoje, eu não pensaria, eu iria. [...] mas, eu acho que eu devo ficar por aqui por um bom tempo". ${ }^{36} \mathrm{O}$ seu posicionamento não descartou em definitivo outra migração, mesmo com a família vivendo no Paraná e de sua situação estável no emprego, bem como dos desafios que estaria vivendo: "Eu não sei, porque eu estou estudando". E, por fim, a possibilidade em aberto: “Eu tô estudando, de repente um concurso, um concurso público e vai trabalhar como professor em tal área". ${ }^{37}$ Aqui também cabe destacar que a possibilidade alcançada com a estabilidade no emprego de viajar de férias supra, em parte, o espírito aventureiro:

De repente, eu sou meio aventureiro mesmo. Agora, uma coisa que eu não abro mão é de conhecer novos lugares. Por exemplo, agora, eu tô buscando a estabilidade, agora. Eu tô com cinco anos trabalhando nessa empresa, então eu tenho uma estabilidade. Agora, depois de quinze anos de casado que eu consegui comprar minha casa própria. Então eu acho que agora eu vou dar uma aquietada por aqui, mas conhecer lugares pra passear, me aventurar, isso é um projeto de vida. ${ }^{38}$

Em certa medida, viver no Paraná permitiria então, agora com a estabilidade alcançada, poder viajar, ou ainda, se manter aventureiro a despeito do lugar de moradia. 0 exemplo de Marcio demonstra um tipo de migração pouco preocupada com o retorno, ou seja, de um retorno não planejado, embora ele sempre estivera nas suas expectativas.

As interpretações dessas entrevistas demandaram análises dos discursos apropriados pelos entrevistados, como aquele referente ao processo de construção de fronteiras, do progresso, do espírito aventureiro, da cultura migratória familiar e do desejo da conquista econômica. Da mesma forma, demandou atenção à maneira como os entrevistados destacaram os imprevistos que escaparam ao seu planejamento de vida, como a saudade

\footnotetext{
${ }^{35}$ Idem.

${ }^{36} \mathrm{Idem}$.

${ }^{37}$ Idem.

${ }^{38}$ Idem.
} 
de casa, estudo dos filhos, o reatar de relações amorosas e a doença ou o falecimento de familiares.

Alguns entrevistados procuraram ler essa realidade de maneira mais estrutural, como um resultado das políticas do Estado, antes impulsionador, hoje responsável pela falência dos negócios. Outros relacionaram sua trajetória ao ganho cultural e profissional e trouxeram questões familiares como preponderantes para o retorno, seja no caso do retorno por opção ou mesmo do forçado.

A divisão dos três grupos com os quais apresentamos o retorno poderia ser analisada por outras características, e esta divisão apenas indicou uma tentativa mediante a multiplicidade de situações que envolveram os fenômenos de deslocamento. Cada uma das entrevistas apresentou particularidades objetivas, materiais, e as respectivas interpretações, subjetivas. Serve tal apontamento para o caso dos entrevistados que definiram um prazo para o retorno e necessitaram repensá-lo durante o processo migratório; para aqueles que não pretendiam voltar; ou para aqueles que pouco se preocuparam com a definição do retorno, embora contassem com a sua possiblidade.

\section{Considerações finais}

Procuramos tratar das motivações - divididas - do retorno e seguimos com a análise da atual situação dos migrantes, no pós-retorno, e daquilo apresentado como herança da migração, de algo resultante do espaço disputado e conquistado, algo a ser apresentado, inclusive, àqueles que ficaram.

Optamos por apresentar os sujeitos a partir de uma condição ou mesmo de um estado, qual seja, o de migrante - o migrante a partir dos estudos e de fluxos demográficos, e o migrante pela perspectiva histórico-antropológica das memórias da migração. E, para ambas as abordagens, o migrante pelas três categorias estruturantes da nossa análise, sendo elas: a memória, a territorialidade e a condição do retorno. Entre "o lá e o cá", o retorno implicou olhar/ lembrar dos lugares, num processo marcado por imaginação e construção de territórios, seja ele espacial ou simbólico, narrado agora, diante das novas relações estabelecidas no retorno.

Quanto ao esforço do IBGE no seu questionário experimental, o de utilizar de categorias centrais da ambiência da migração (resumidas pelo trabalho, estudo, saúde, dificuldades com moradia, conflitos familiares, violência e acesso a bens e serviços, conforme apresentamos no início do texto), destacamos que supostamente estas categorias interferiram de diferentes maneiras e graus de adesão nas escolhas pela migração de saída e de retorno; inclusive, 
fariam sentido se fossem cotejadas as respostas destes dois momentos, o da saída e o do retorno. Todavia, mais do que a resposta objetiva que constaria no questionário, a relação entre análise estatística e a histórico-antropológica, assim acreditamos, envolve a problematização das trajetórias narradas, aqui alcançadas num recorte reduzido de 25 sujeitos entrevistados, por sua vez, representadas pelas três entrevistas citadas. O conteúdo dessas entrevistas corroborou a leitura da polissemia de formas de se lidar com o retorno, algo que não nos impediu de apresentar uma proposta de categorização.

Pontualmente, nosso caminho para apresentação de uma relação entre a estatística e a abordagem antropológica pautou-se em uma tentativa de categorização do retorno e seguiu o seguinte trajeto: primeiro - contextualizar as memórias a partir das indicações estatísticas; segundo - dialogar com os usos da narrativa, aqui compreendida pelo estudo da memória e pela própria metodologia da História Oral; terceiro - abordar teoricamente as categorias estruturantes do estudo dos itinerários da migração, sendo elas, uma espacial- aqui seguida pelo conceito de território - e uma referente ao estado do sujeito - aqui a da condição de migrante diante da perspectiva do retorno. Assim apresentamos os três tipos de retorno, sendo eles, o retorno "planejado", o retorno forçado e o retorno não planejado.

Concluindo, percebemos com as nossas fontes orais que os entrevistados têm a noção do fluxo, notadamente de uma maneira menos específica do que a indicada pelo IBGE, e a propósito desse retorno em massa destacam exemplos de outras famílias que retornaram. Os entrevistados apresentam como explicações para o retorno justificativas que vão do econômico, passando pela dificuldade de adaptação cultural, aos problemas de saúde..$^{39} \mathrm{Cabe}$ ressaltar que outros fluxos foram apresentados no conjunto das entrevistas, das quais as três ora apresentadas fazem parte. Foi o caso das frentes migratórias que envolveram a região Sul, vivenciadas pelos pais, e região da Amazônia Legal, dos paranaenses que antes dos entrevistados para lá migraram ainda na década de 1970 e 1980. Em todos os casos, a relação entre estatísticas e fontes orais não se tratou apenas de "um problema do pesquisador", mas também dos entrevistados ou da historiografia. ${ }^{40}$

Em algumas situações a narrativa dos lugares que compunham os itinerários se deu de forma mítica, romanceada. Já em outras, de modo trágico; e, em poucas vezes, de maneira irônica. Essas narrativas supostamente

\footnotetext{
${ }^{39}$ Essa consciência não foi uma regra entre os entrevistados e algumas entrevistas se referiram a escolhas individualizadas, sem se estabelecer um diálogo com a realidade de outros migrantes.

${ }^{40}$ VILANOVA, op. cit.
} 
substituiriam em parte a cronologia e a necessidade de falar de conjunturas políticas e econômicas, atribuídas ao domínio do historiador/entrevistador. Em outras palavras, tratou-se de uma questão de autoridade para narrar. Foi essa a relação que marcou a condução das entrevistas; tipo de situação potencializada quando falavam a um historiador que vivenciou os lugares comuns apresentados nos itinerários do processo migratório.

Diante desse posicionamento concluímos que de diferentes formas e expectativas os fluxos migratórios fizeram parte das narrativas sobre o retorno. A apresentação de memórias do retorno e o seu cotejamento com estudos da conjuntura demográfica organizou nossa categorização do retorno numa tentativa de superação de conclusões meramente esquemáticas. Antes, foi a dialogicidade que marcou epistemologicamente a construção e interpretação das entrevistas, narradas no e pelo retorno e pautada pelos diferentes modos de se lidar com a angústia do retorno e com as formas de apresentação territorial do itinerário da migração.

Artigo recebido para publicação em 08/07/2019 Artigo aprovado para publicação em 19/05/2020 